\title{
A Study Of Upper Cleft Lip Cases In Telangana Zone (Andhra Pradesh, India)
}

\author{
S.Deepthi ${ }^{1}$,Dr.S.Saritha ${ }^{2}$, Dr.D.Suseelamma, ${ }^{3}$ \\ Lecturer $^{1}$ and Professor ${ }^{2}$, Department of Anatomy, KIMS , Narketpally,
}

\begin{abstract}
Cleft lip (Cheiloschisis) is a most common congenital facial anomaly. It is due to non fusion of maxillary process with medial nasal processes (Globular process). A cleft lip can be either unilateral (or) bilateral. The oral clefts are congenital anomalies caused by the interaction between genetic and environmental factors. The abnormal craniofacial morphogenesis leads to various types of oral clefts. The oral clefts result from failure of migration of neural crest cells (or) non fusion of the facial prominences between $4^{\text {th }}$ and $8^{\text {th }}$ weeks after conception. During the germinal stage the embryo is most susceptible to environmental factors predisposing to clefts.

Keywords: Cleft lip, Globular process, Maxillary process, Neural crest cells.
\end{abstract}

\section{Introduction}

A cleft is a fissure or opening or a gap. It is the non-fusion of the body's natural structures that form before birth In decades past, the condition was sometimes referred to as harelip, based on the similarity to the cleft in the lip of a hare, Cleft lip or palate can be successfully treated with surgery soon after birth or early childhood. (Tessier.p ${ }^{11}$

\section{Incidence:}

Most cases of Cleft lip are multifactorial. Cleft lip (Approximately1/1,000 births) occurs more frequently in males $80 \%$ than in females, its incidence increases slightly with maternal age. If normal people have one child with a cleft lip, the chance that the next baby will have the same defect is $4 \%$. If two siblings are affected, the risk for next child in $9 \%$.(T.W.Sadler) ${ }^{3}$

ANATOMY OF LIP

VERMILION ZONE - Reddish part of the lip. It is vascular through thin moist epithelium.

VERMILION BORDER - Muco cutaneous junctional region where skin and vermilion zone meet.

PHILTRUM - A shallow groove in the median part of upper lip.

FRENULUM- Median fold connecting each lip to corresponding gum.

These are mobile muscular folds surrounds the oral cavity ${ }^{3}$

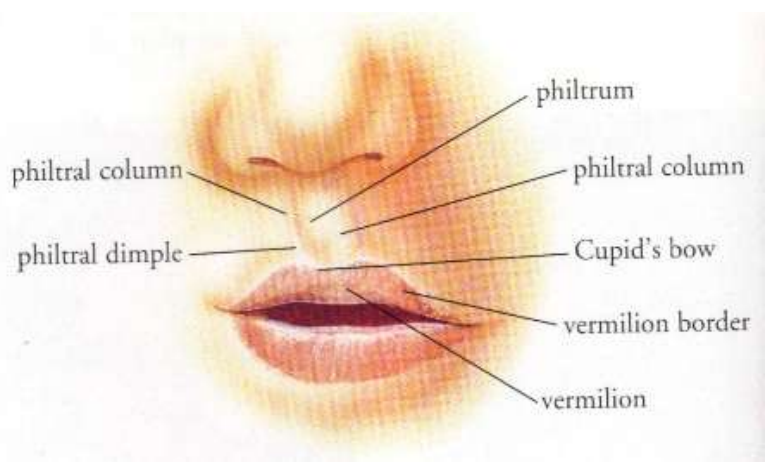

\section{Movements Of Theupper Lip}

Elevator And Retractor Of Upper Lip:

1. Lavator labii superioris alaque nasi muscle

2. Levator labii superioris muscle

3. Zygomaticus major and minor muscle

4. Levator anguli oris muscle

5. Risorius muscle 


\section{Spincters:}

1. Orbicularis oris

2. Buccinators.

Buccinators helps on manipulate food and also provides the resistance necessary for blowing.

Abnormalities in cleft lip are the direct consequence of disruption of the muscles of the upper lip and Naso labial region ${ }^{4}$

Cleft lip and palate are common defects that result in abnormal facial appearance and defective speech. Such defects are due to partial or complete lack of fusion of the maxillary prominences with medial nasal prominences.(T.W.sadler 2010$)^{3}$

The external appearance of face is formed between $4^{\text {th }}$ to $10^{\text {th }}$ weeks of intrauterine life. It is formed by the fusion of five prominences around the stomodeum. The front nasal lying cranially, two maxillary processes laterally and two mandibular processes caudally in relation to stomodeum. The mesenchyme of the frontonasal process receives the neural crest cells from forebrain and midbrain, while maxillary and mandibular prominences associated with first pharyngeal arch receive the neural crest cells from midbrain and hindbrain (Rani kumar2012)

\section{Developmental sources of upper lip:}

1) Philtrum develops from the globular process.

2) The right and left sides of the lip develop from the respective maxillary process.

The labial branches of infra orbital nerve alone supply the skin of the upper lip which develops from both frontonasal and maxillary process.

\section{Three types of defects are recognized,}

a) Central cleft lip develops due to failure of the globular process of each other.

b) Unilateral cleft lip develops due to failure of fusion of maxillary process of one side with the corresponding globular process.

c) Bilateral cleft lip is caused due to failure of fusion of the maxillary and globular processes on both sides.(Neeta kulkarni $2012^{6}$

Children with midline clefts of the lip often have mental retardation. Median clefts are associated with loss of other midline structures, including those in brain, in its extreme form entire cranial midline is lost, lateral ventricles of the cerebral hemispheres are fused in to a single ventricle head is narrow is called as holoprosencephally.

\section{Materials And Methods}

We have collected 30 cleft lip cases of different ages (six months to 35 years), including both the sexes (males 20, females 10) from department of surgery in Kamineni Institute of Medical Sciences Narketpally, Nalgonda Dist. and G.S.R Hospital Hyderabad.

According to below the Proforma

1. Name;

\section{Proforma}

2. Age:

3. Sex:

4. Address:

5. Family history

a) Father Name, Occupation \& Age

b) Mother's Name, Occupation \& Age

c) Any history of congenital anomalies including clefts among the parents \&sibling

d) H/O hypertension, diabetes, thyroid or consanguinous marriages

6. Socioeconomic Status:

7. Obstetric $\mathrm{H} / \mathrm{O}$ including abortions any $\mathrm{H} / \mathrm{O}$ fever during pregnancy \& any habits \& treatment taken:

8. Type of gravid arum

9. Present Illness: Regarding the cleft upper lip and its treatment

\section{Observations}

The present study 30 cases were observed 


\section{Pie Charts}

CLEFT LIP ACCORDING TO SEX

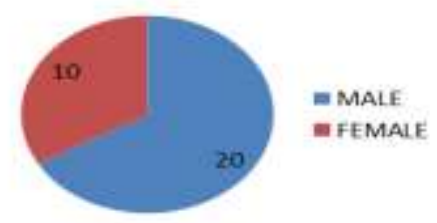

ACCORDING TO AGE

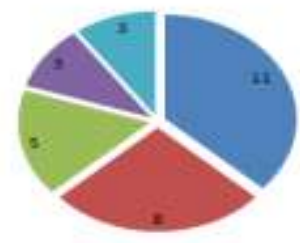

FROMBARTH.

$\begin{aligned} & \text { IYEAR } \\ = & \text { 1YEAG-SYEARS }\end{aligned}$

= STEAAS-1OYEARS

1OVEARS-

2OYEARS
$=$ ABOVEZOVEATS

FACTORS INFLUENCE THE CLEFTLIP

STATISTICAL ANALYSIS

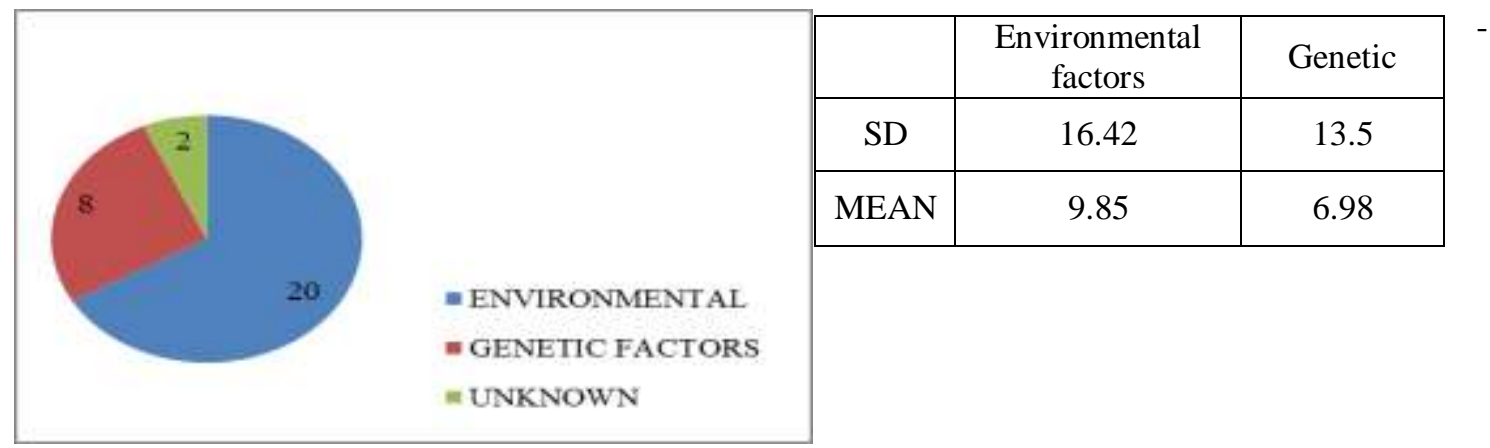

\section{Classification of cleft lip- I}

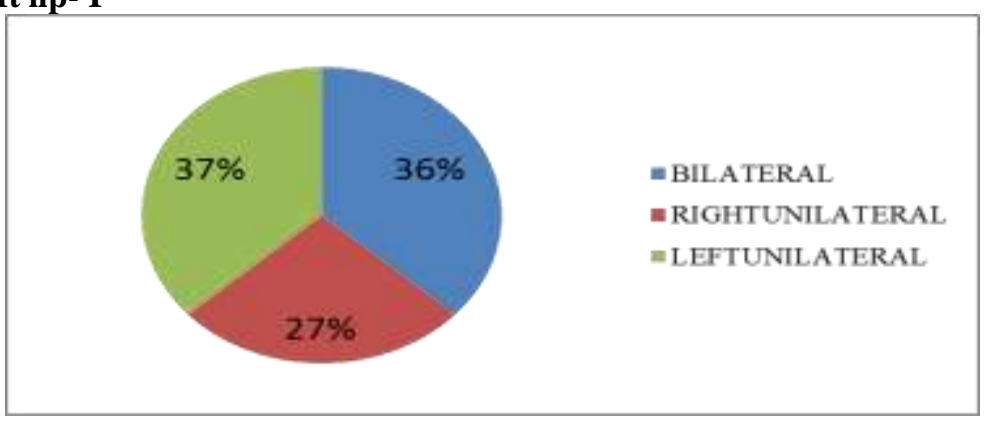

CLASSIFICATION OF CLEFTLIP-II

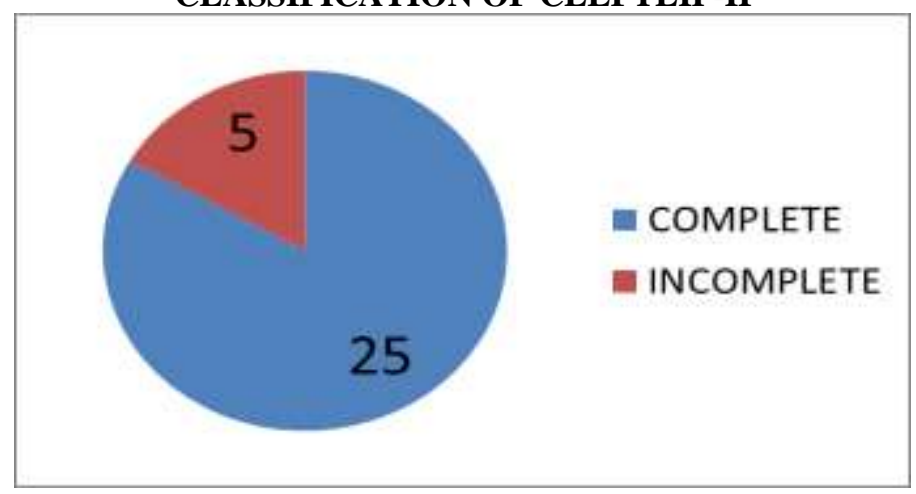

IV. Discussion

Face is the most important prominent visual object in our social environment. The expression of the face is a basic mode of nonverbal communication among people. The face is formed by the shapes and placement of the bones of the skull, the cartilage, and the soft tissues, including the muscles, fat, and skin. All the facial expressions are built upon the foundation of bone and Muscle. Cosmetic surgery can be used to alter the appearance of the facial features. ${ }^{1}$ Plastic surgery may also be used in cases of facial trauma and repair of cleft lip. Severely disfigured individuals have recently received full face transplants and partial transplants of skin and muscle tissue ${ }^{7}$ 
Neural crest cells are essential for formation of much of the cranio facial region. Consequently, disruption of crest crest cell development results in severe craniofacial anomalies since crest cells also contribute to the cronotruncal endocardial cushions, which septate the out flow tract of the heart in to pulmonary aortic channel s,many infants with craniofacial defects also have cardiac abnormalities. ${ }^{3}$

The specific area in the human genome caught the scientists' attention. 'This was a point on the long arm of chromosome 8, where the cleft group conspicuously often had a variant, far more frequently than people who had no abnormality,' Dr. Elisabeth Mangold, a lecturer from the Institute of Human Genetics at the University of Bonn, explains this is a notable clue. The human geneticists from the University of Bonn had examined the DNA of 460 persons with clefts. The gene located in this region has something to do with the occurrence of clefts. ${ }^{8}$

In the August 19, 2004, issue of the "New England Journal of Medicine," an international team of researchers studied families from ten populations to understand the role of genetic mutations in cleft deformities. The study identified a variant in the gene encoding interferon regulatory factor 6 (IRF6) as a major contributor to cleft lip and cleft palate in Van der Woude's syndrome. Van der Woude's syndrome is an autosomal dominant cleft deformity caused by the substitution of isoleucine for valine at amino acid position 274. This substitution interferes with the gene function resulting in cleft abnormality as well as tripling the risk of the cleft abnormalities in affected families ${ }^{9}$

Consanguinity is considered a significant factor in autosomal recessive diseases; it has also been associated with congenital anomalies such as cleft lip. The risk of congenital conditions is higher in subjects born of first degree consanguineous parents compared with those of non-consanguineous marriages.$^{10}$

The present study out of 30 cases 8 cases were due to genetic factors. The parents were of consanguaous marriages.

A number of environmental factors also influence \& been identified that may increase a child's chance of being born with a cleft lip These are Lack of folic acid, Smoking, Consumption of alcohol \&retinoids, Maternal hypoxia, hypertension, Anti convulsant medication during pregnancy.

All pregnant women are advised to take a daily supplement of folic acid during the first four months of pregnancy. Folic acid helps reduce the possibility of birth defects. One of the studies found that the risk of having a child born with cleft lip or palate was more than four times higher if mothers did not take folic acid in the first three months of pregnancy ${ }^{11}$.

In our study 7 cases were under low socioeconomic condition the mother did not take folic acid during pregnancy.

Women who consume higher quantities of alcohol before and during pregnancy show, an increase risk for having babies with oro facial clefts, Some studies have shown a link between a mother's alcohol consumption during pregnancy and the development of a cleft lip or palate in her baby.

Anticonvulsant medications such as phenobarbital, trimethadione, valproate, and dilantin have been documented to increase incidence of cleft lip and/or cleft palate (AR dinger 1988, Feldman 1977, Hanson 1976, Hanson 1984, Holmes 2004, Kallen 2003, Meadow 1970, Wyszynski 1996, Jackal 1975).

Scientist found the pregnant women who smoked also carried foetus that lacks the glutathione $\mathrm{s}$ transferase enzyme much more likely to give birth a baby with a cleft This enzyme plays roles in common detoxification process. $^{12}$

Deficiency of super oxide dismutase and catalase enzymes are responsible for scavenging free radicals that damage neural crest cells . Loss of migration of neural crest cells as a result oroclefts are formed.

The present study had 12 cases caused by environmental factor ,that included alcohol consumption ,smoking and medication during pregnancy

Increase in Age of the father is one of the factors for cleft lip. Bille et.al ${ }^{12}$ studied 2,876 Danish babies born with isolated oral clefts in that 1,920 babies had cleft lip and 956 infants with cleft lip and cleft palate Based on this analysis scientists determined the increase age in the both parents increases the risk factor for oral clefts $^{13}$.

Neural crest cells are easily killed by consumption of retinoids during pregnancy . Retinoids are effective in treating acne which is common in young woman of child bearing age great care should be employed before describing the drug to this cohart.

According to the present study out of 30 cases , 7 cases had increase in age of the parents which was above 35 years old and their children had cleft lip.

\section{Conclusion}

Lip and palate are both essential for speech; individuals with cleft usually need the aid of speech therapy. Surgical intervention is must, individual for socialization with family and community. Supporting the parents as well as for the child is pivotal in management. 
The present study included 30 cases. Cleft lip is due to lack of attachment of naso labial muscle. The known environmental factors in the genesis of this defect were 20 cases that included male-14 and female6cases.Considering the high incidence of cleft lip in this region may due to environmental factors, leading to role of a mutated gene in the causation of this defect, during time of pregnancy.

Neural crest cells are important for craniofacial development because they provides the patterning pf the facial muscles.

The first 2- 3 months after birth, surgery performed to close the cleft lip. While to repair a cleft lip can be performed soon after birth often preferred age is at approximately 10 weeks of age following rule of $10 \mathrm{~s}$ coined by surgeon Wilhelmmesen and Musgrave in 1969. The baby is at least10 weeks of age, weight at least 10 pounds, and has $10 \mathrm{~g}$ haemoglobin.

\section{Aknowledgemant}

I Thankful to Dr . Srinivas Reddy Gosla, Dr.Ashwini, and Ms.Mercy GSR Hospital for allowing me to collect cases for my article.

\section{References}

[1] Tessier.p (June1976)Anatomical classification, facial, craniofacial, lateral facial clefts J.Maxillo facial sur(2):69-92 doi 10.1016)/s0301-0503(76) 80013-6.

[2] Lip Wikipedia free encyclopaedia 28 November 2012 at 12:13

[3] T.W. Sadler Longman's medical embryology Lippincott Williams \& Wilkins $11^{\text {th }}$ edition 2010. Page no;284,358.

[4] Proffesional health systems, muscles of facial expression 2012.

[5] Rani Kumar Human embryology ISBN 978-81-92220-04 , 2012, PAGENO;104

[6] Neeta V Kulkarni, clinical anatomy (A problem solving approach)2 ${ }^{\text {nd }}$ edition2012 page No;323.

[7] Introduction to data face site ; Facial Expressions, nonverbal communications, physiognomy data face 2003 by joseph

[8] Texas department birth defect risk factor series oral clefts

[9] cleft lip and palate- scientist discover the gene locus associated with deformitymarch13,2009.

[10] New England Journal of Medico"; Interferon Regulatory Factor 6 (IRF6) Gene Variants and the Risk of Isolated Cleft lip and palate.

[11] Study of patients with cleft lip and palate with consanguineous parents original article Si bele Nabs cimento de Aquino et.al, Braz -journal oto rhinolaryngeal,2011 $771 ;(19-23)$

[12] Ramsay pharmacy Ltd NHS Cleft lip \& palate causes2007

[13] Causes of CleftlipNHS9070, 2012

\section{ILLUSTRATIONS PREOPERATIVE}

\section{POSTOPERATIVE}

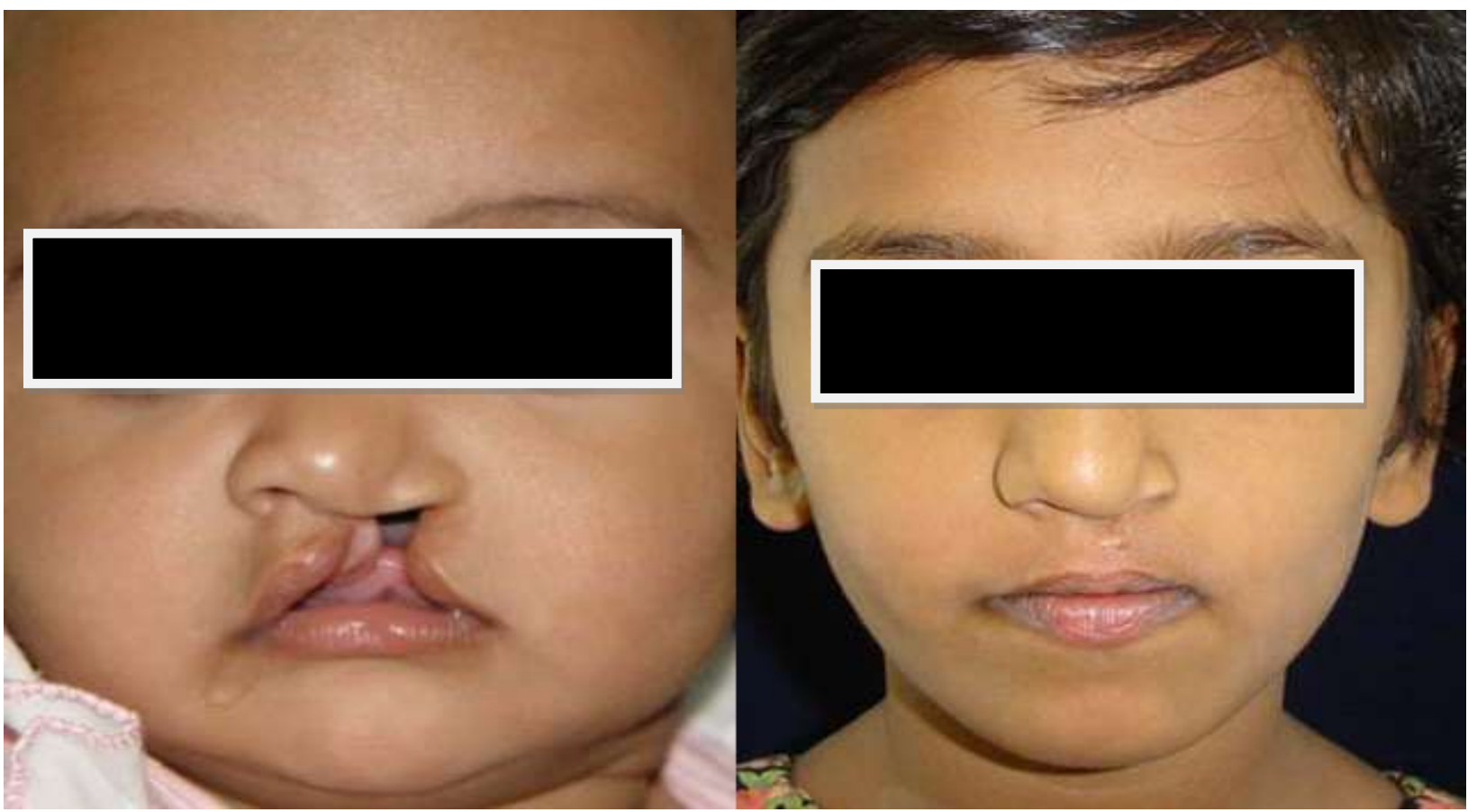

1)Photograph showing left unilateral complete cleft lip, alveolus, hard and soft palate,this defect causes deformed nose along with the lip. This left nostril is distorted and there is also a disruption of orbicularis oris muscle(courtesy by GSR Institute of cranio facial and facial plastic surgery) 

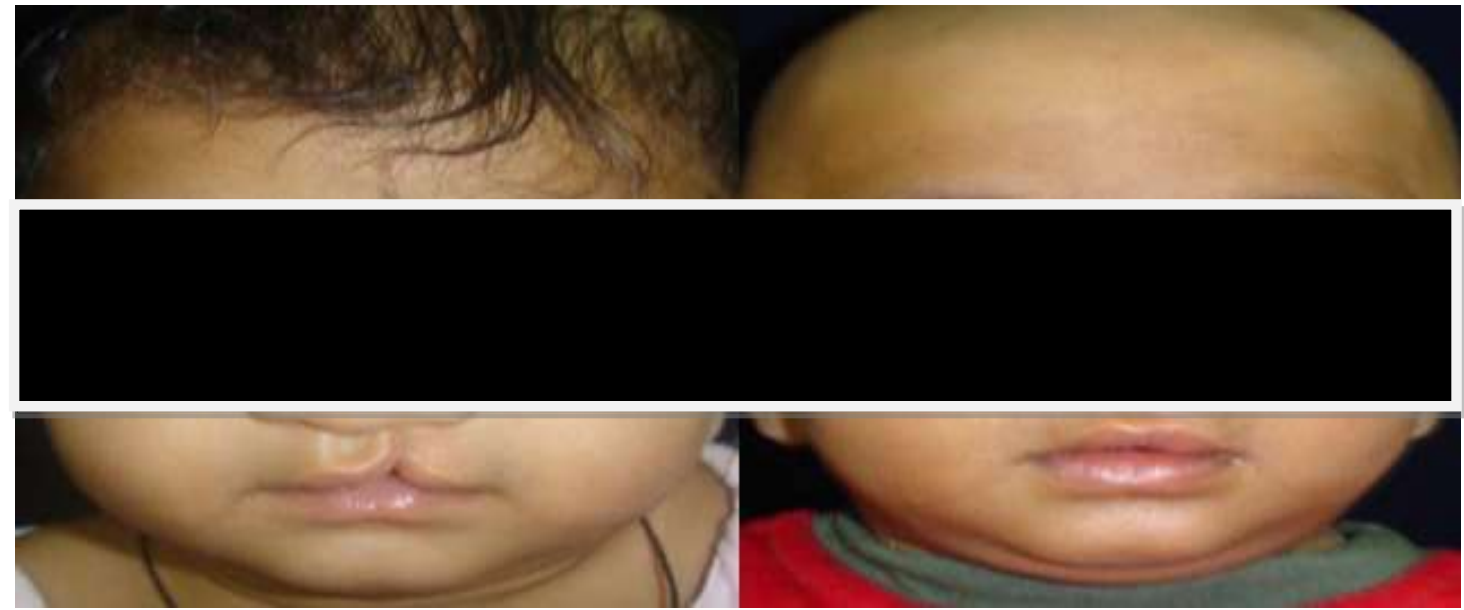

2)Photograph showing left unilateral in complete cleft lip here there is disruption of the continuity of the orbicularis oris muscle. The nose is not affected.(photograph courtesy by GSR Institute of craniofacial and facial plastic surgery)

\section{PREOPERATIVE}

POSTOPERATIVE

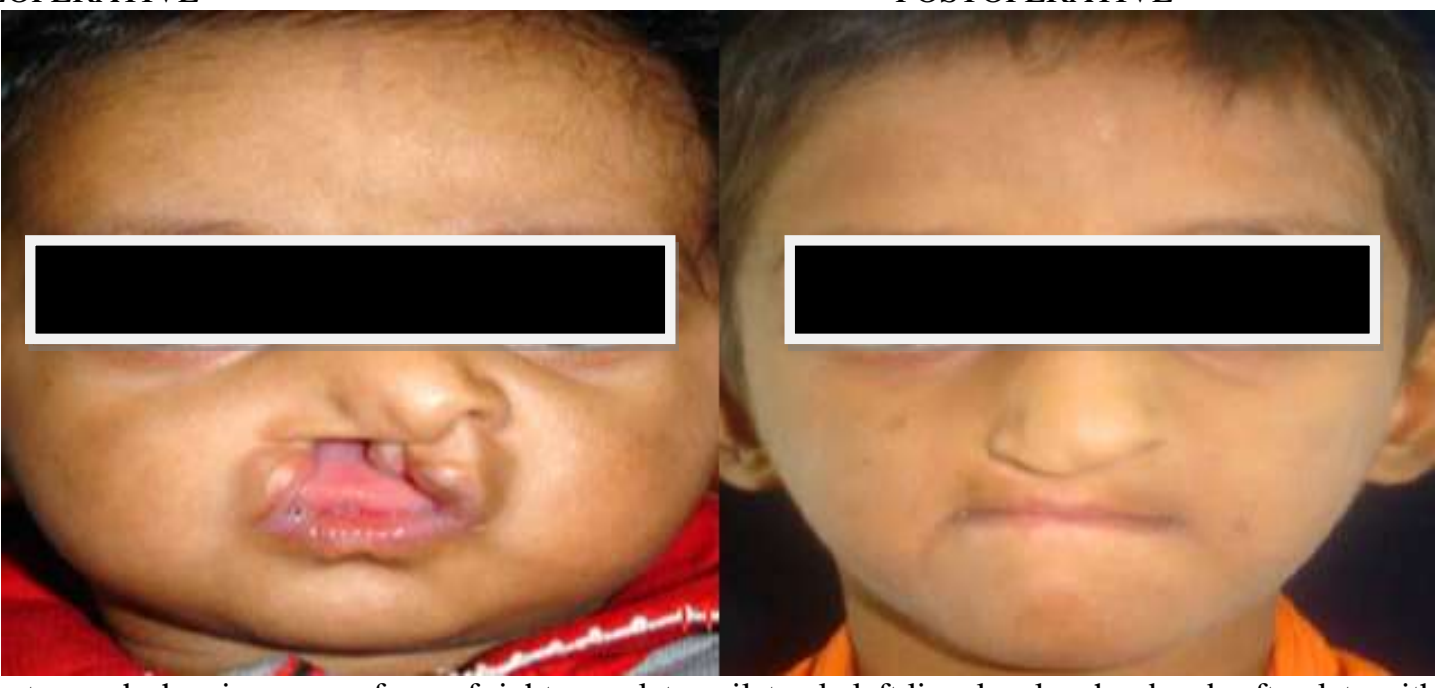

3) Photo graph showing severe form of right complete unilateral cleft lip ,alveolus, hard and soft palate with a severe disrupted philtrum ,deformed nasal septum, right nostril ,distortion of nasolabial and bilabial rings disrupted on right side.(Photograph courtesy by GSR Institute of cranial facial and facial plastic surgery)

\section{PREOPERATIVE}

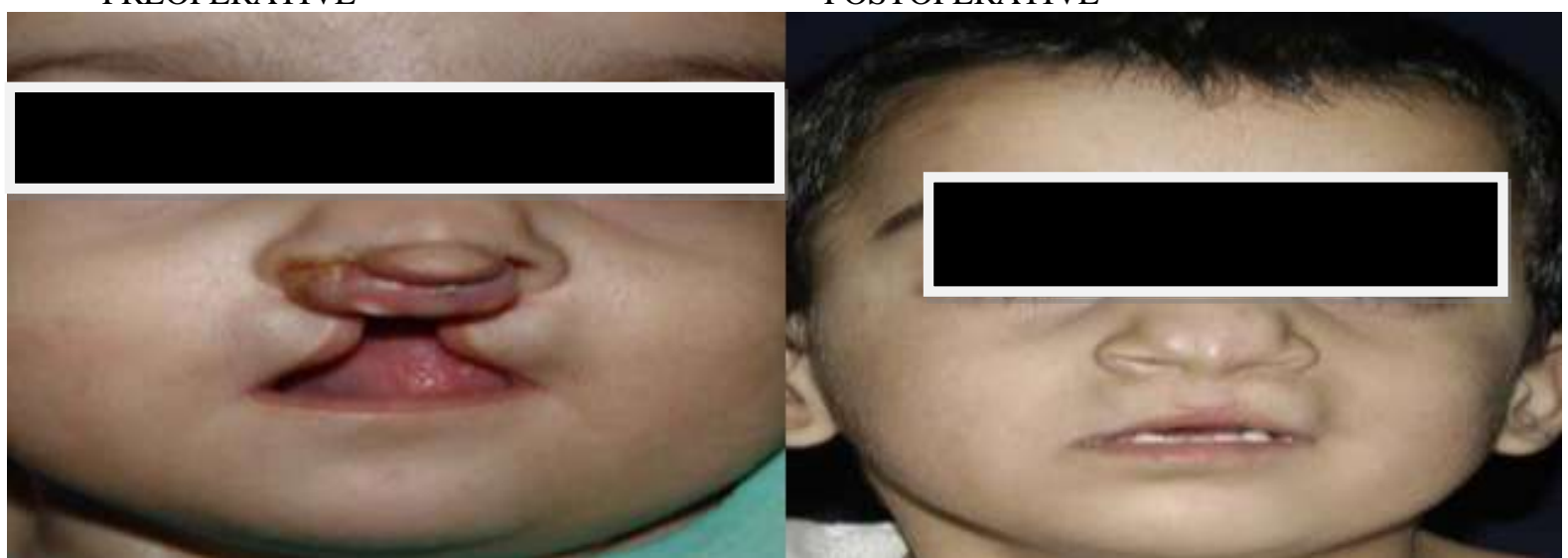

4)Photograph showing bi lateral complete cleft lip,alveolus, hard and soft palate. The alveolar ridge is separated completely on both sides. The bony portion is called as prolabium. The skin and mucosa covering the premaxilla called as prolabium (Courtesy by GSR Institute of cranio facial and facial plastic surgery) 